\title{
Carbon Emissions Reduction and Power Losses Saving besides Voltage Profiles Improvement Using Micro Grids
}

\author{
Rashad M. Kamel, Aymen Chaouachi, Ken Nagasaka \\ Environmental Energy Engineering, Department of Electronics \& Information Engineering, Tokyo University of Agriculture and \\ Technology, Tokyo, Japan. \\ Email: r_m_kamel@yahoo.com, a.chaouachi@gmail.com,bahman@cc.tuat.ac.jp
}

Received July 21 ${ }^{\text {st }}, 2010$; revised August 27 ${ }^{\text {th }}, 2010$; accepted August $27^{\text {th }}, 2010$.

\begin{abstract}
The objective of this paper is to evaluate the value of enhancement in voltage, amount of emission reduction and amount of power losses saving with using micro grids. The paper is divided in two parts, the first part evaluates the voltage improvement and power losses saving with micro $(\mu)$ sources (distributed generators like fuel cell, micro turbine, solar cell, wind turbine etc.). The obtained results indicate that using $\mu$ sources reduce voltage drop by about $3 \%$, Also, it is found that using $\mu$ sources can reduce the power losses to more than one third of its value without using $\mu$ sources. The voltage at the buses near the $\mu$ sources location will suffer from small drop than the buses far from $\mu$ sources locations. The second part calculates amount of $\mathrm{CO}_{2}, \mathrm{SO}_{2}, \mathrm{NO}_{x}$ and particulate matters emissions from main grid and from $\mu$ sources which forms micro grid. The results indicates that more penetration of $\mu$ sources in the power systems especially the renewable sources (solar and wind) will help in reducing or removing emission problems and solve the green house gas problems. Finally this paper proved with calculations that the micro grid can solve most of the problems which facing the conventional power system and keep the surrounding environment clean from pollution and the micro grid will be the future power system.
\end{abstract}

Keywords: Micro Grid, Voltage Enhancement, Losses Saving, $\mathrm{CO}_{2}, \mathrm{SO}_{2}, \mathrm{NO}_{x}$ and Particulate Matter Emissions

\section{Introduction}

Increasing penetration of distributed generation (DG) resources to the low voltage (LV) grids, such as Photovoltics, CHP micro-turbines, small wind turbines areas and possibly fuel cells, alters the traditional operating principle of the grids. A particularly promising aspect, related to the proliferation of small-scale decentralized generations ( $\mu$ sources), is the possibility for parts of the network comprising sufficient generating resources to operate in isolation from the main grid, in a deliberate and controlled way. These are called micro grids and the study and development of technology to permit their efficient operation has started with a great momentum [1-3].

With the efficient integration of small scale distributed generation into LV system and ability of supplying its own local demand customers, exporting energy to neighbor's systems and providing ancillary services (flow management, voltage and frequency control capabilities) to the public systems, the development of micro grids has potential to bring a number of benefits into the system in term of [4]:

- Enabling development of sustainable and green electricity: Clearly, electricity generated by renewable energy sources can substitute electricity supplied by conventional power plants with many benefits such as carbon emission reduction, reducing dependency on depleting fossil sources and sustainable and "free" energy sources which in the long term brings lower energy prices.

- Enabling larger public participation in the investment of small scale generation: Economic appraisal for installing micro generation will likely require less complex analysis in contrast to large generation. With much smaller magnitude in the investment, and less complexity in trading electricity, the financial risks exposed to the investors are much lower. At a domestic level, the decision to invest in such generation may be less motivated by financial gain and influenced by Individual's will to 
contribute for clean environment. This will clearly enable larger public participation in contributing to the deployment of Renewable Energy Sources (RES) in the form of micro generation.

- Reduction in marginal central power plants: Micro generation can displace the capacity of peak load or marginal central power plants.

- Improved security of supply: With a considerable large number of installed micro generation, the total generation margin increases. This will also directly increase the available capacity of supplying peak load condition.

- With a large number of generators, failure in a number of small generators will not have a considerable impact on the capability of supplying the demand. This is in contrast to systems which rely on a relatively small number of big generators. A failure of one large generator may cause significant generation deficit and may lead to load shedding. Micro generation technologies also bring more diversity in the types of fuel that can be used to generate electricity. This is likely to increase the security of supply and reduce dependency on a particular type of fuel $[5,6]$.

- Reduction of losses: Currently, losses in a system which primarily relies on central generation are typically around $7 \%-10 \%$ of total electricity consumption per year ${ }^{[4]}$. The magnitude of losses is influenced by many factors such as the proximity of generation to loads, circuit impedances, loads, and profiles of loading in each circuit among others. Bearing in mind that losses are a quadratic function of the current, the largest losses occur during peak loading conditions of the circuit. As micro grid is able to supply its loads locally, it reduces the amount of power transfer from remote generation via transmission and distribution circuits. Hence, it will reduce system losses. This also leads to the reduction of total energy produced by central power plants. Thus, it will also reduce Pollutants $\left(\mathrm{CO}_{2}, \mathrm{NO}_{\mathrm{x}}, \mathrm{SO}_{2}\right.$ and other particulate matter) from these plants.

- Enabling better network congestion management and control for improving power quality: The introduction of micro generation in the LV networks will provide better capability of controlling power flows from the LV systems to the upper voltage networks. Hence, it may avoid the need for reinforcing the networks due to network congestion or voltage problems.

Based on the previous discussion, using micro grid will help on voltage improvement, emission reduction and power losses saving. Many papers discussed the effect of micro grid on voltage improvement, power losses reduction and emission reduction, but quantifying amount of improvement or reduction is not considered. The main goal of this paper is to evaluate the effect of the micro grid on voltage enhancement, emission reduction and losses saving. To conduct the proposed studies, the benchmark networks used for analysis and its data are described in Section 2 [single feeder and multi feeder networks]. Section 3 presents the daily load curves of the one feeder network (residential load) and three feeders network with three types of loads (residential, industrial and commercial loads). Section 4 shows the effect of the micro grid on voltage improvement and power losses saving for single feeder and multi feeders networks. Amount of emission reduction due to using micro grid is given in Section 5. Conclusions are stated in Section 6.

\section{Benchmark Network Used for Analysis}

Bench mark network described in references [3] and [7] is used for analysis. Single line diagram with all buses marked is shown at the end of the paper (Figure 12). One feeder network includes 7 buses (buses 1-7) represent the residential loads. Industrial load (bus 8) represents the second feeder. The remaining buses (buses 9-16) feed commercial loads and represent the third feeder. Impedance of the network lines, data for $\mu$ sources used and renewable power time-series used [output KW/Installed $\mathrm{KW}$ ] are given in Tables 1-3 respectively [7].

The units have been calculated in power base of 100 KVA and voltage base $400 \mathrm{~V}$. Bus 0 represents the main grid (distribution network).

Micro turbine is located at bus 7, fuel cell is located at bus 6 , and $\mathrm{PV}_{3}$ is located at bus 5 while wind turbine and $\mathrm{PV}_{2-5}$ are connected to bus 4 .

\section{Daily Load Curves for Single and Multiple Feeders Networks}

Aggregate daily load curves for single feeder (residential loads) and three feeders (residential, industrial and com-

Table 1. Line data for micro grid.

\begin{tabular}{cccc}
\hline Sending Bus & $\begin{array}{c}\text { Receiving } \\
\text { Bus }\end{array}$ & R (p.u.) & X (p.u.) \\
\hline 0 & 1 & 0.0025 & 0.01 \\
1 & 2 & 0.0001 & 0.0001 \\
2 & 3 & 0.0125 & 0.00375 \\
3 & 4 & 0.0125 & 0.00375 \\
4 & 5 & 0.0125 & 0.00375 \\
5 & 6 & 0.0125 & 0.00375 \\
3 & 7 & 0.021875 & 0.004375 \\
1 & 8 & 0.033125 & 0.00875 \\
1 & 9 & 0.0075 & 0.005 \\
9 & 10 & 0.015 & 0.010625 \\
10 & 11 & 0.02125 & 0.005625 \\
11 & 12 & 0.02125 & 0.005625 \\
9 & 13 & 0.010625 & 0.005625 \\
13 & 14 & 0.010625 & 0.005625 \\
10 & 15 & 0.023125 & 0.00625 \\
15 & 16 & 0.023125 & 0.00625 \\
\hline
\end{tabular}


Table 2. Data of the used $\mu$ sources.

\begin{tabular}{cccc}
\hline Unit ID & Unit Name & $\begin{array}{c}\text { Minimum } \\
\text { capacity } \\
(\mathrm{KW})\end{array}$ & $\begin{array}{c}\text { Maximum } \\
\text { capacity } \\
(\mathrm{KW})\end{array}$ \\
\hline 1 & $\begin{array}{c}\text { Micro tur- } \\
\text { bine }\end{array}$ & 2 & 30 \\
2 & $\begin{array}{c}\text { Fuel cell } \\
\text { Wind }\end{array}$ & 1 & 30 \\
3 & PV & 0.1 & 15 \\
4 & $\mathrm{PV}_{1}$ & 0.05 & 3 \\
5 & $\mathrm{PV}_{2}$ & 0.05 & 2.5 \\
6 & $\mathrm{PV}_{3}$ & 0.05 & 2.5 \\
7 & $\mathrm{PV}_{4}$ & 0.05 & 2.5 \\
8 & $\mathrm{PV}_{5}$ & 0.05 & 2.5 \\
\hline
\end{tabular}

Table 3. Renewable power time-series (Output KW/Installed KW).

\begin{tabular}{cccccc}
\hline Hour & $\begin{array}{c}\text { Wind } \\
\text { Power }\end{array}$ & $\begin{array}{c}\text { PV-time } \\
\text { series }\end{array}$ & Hour & $\begin{array}{c}\text { Wind } \\
\text { Power }\end{array}$ & $\begin{array}{c}\text { PV-time } \\
\text { series }\end{array}$ \\
\hline 1 & 0.364 & 0 & 13 & 0.494 & 0.318 \\
2 & 0.267 & 0 & 14 & 0.355 & 0.433 \\
3 & 0.267 & 0 & 15 & 0.433 & 0.37 \\
4 & 0.234 & 0 & 16 & 0.321 & 0.403 \\
5 & 0.312 & 0 & 17 & 0.329 & 0.33 \\
6 & 0.329 & 0 & 18 & 0.303 & 0.238 \\
7 & 0.476 & 0.002 & 19 & 0.364 & 0.133 \\
8 & 0.477 & 0.008 & 20 & 0.373 & 0.043 \\
9 & 0.424 & 0.035 & 21 & 0.26 & 0.003 \\
10 & 0.381 & 0.1 & 22 & 0.338 & 0 \\
11 & 0.459 & 0.23 & 23 & 0.312 & 0 \\
12 & 0.39 & 0.233 & 24 & 0.346 & 0 \\
\hline
\end{tabular}

mercial loads) are shown in Figure 1.

\section{Voltage Enhancement and Power Losses Saving Evaluation with Using Micro Grid}

Load flow program [8] is used to calculate the voltages at all nodes of the micro grid. Results are shown in Figures 2-7. The power factor is 0.85 lagging for residential and commercial consumers and 0.9 for the industrial ones. All calculations have been made at p.u of base $\mathrm{V}_{\text {base }}=$ $400 \mathrm{~V}$ and $\mathrm{S}_{\text {base }}=100 \mathrm{KVA}$. The network data are presented in Sections 2 and 3. It has also been assumed that in the $\mu$ sources the power electronic interface has been adjusted to give or absorb zero reactive power at all buses except fuel cell and micro turbine buses. At all time, we assume that the micro turbine and fuel cell operated at $84 \%$ of their maximum capacity $(25 \mathrm{KW})$, and the renewable sources outputs powers as listed in Table 3. The dashed lines represent results without $\mu$ sources while the solid lines represent results with using $\mu$ sources.

From the above results the following points can be raised:

- With using $\mu$ sources, in the two studied cases (single feeder and three feeder), the voltages at all buses are improved.

- Amount of improvement in case of single feeder network is better than three feeder case because amount

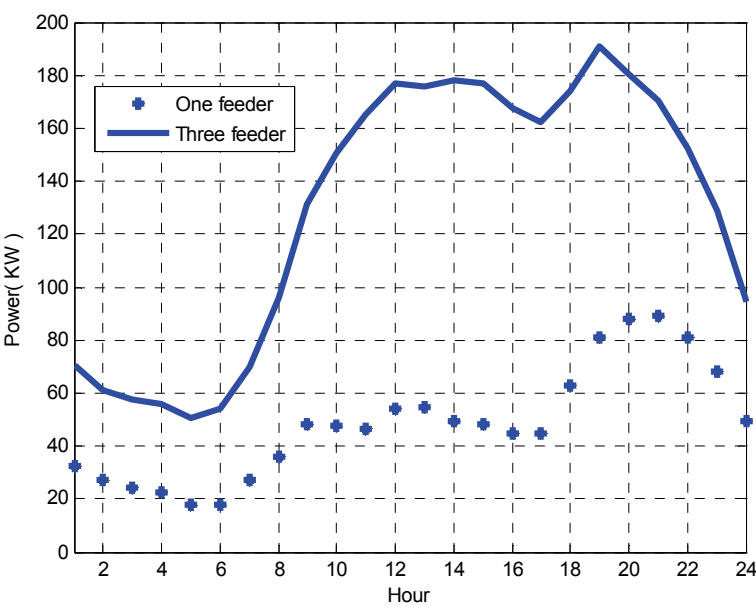

Figure 1. Daily load curves for one feeder and three feeders networks.
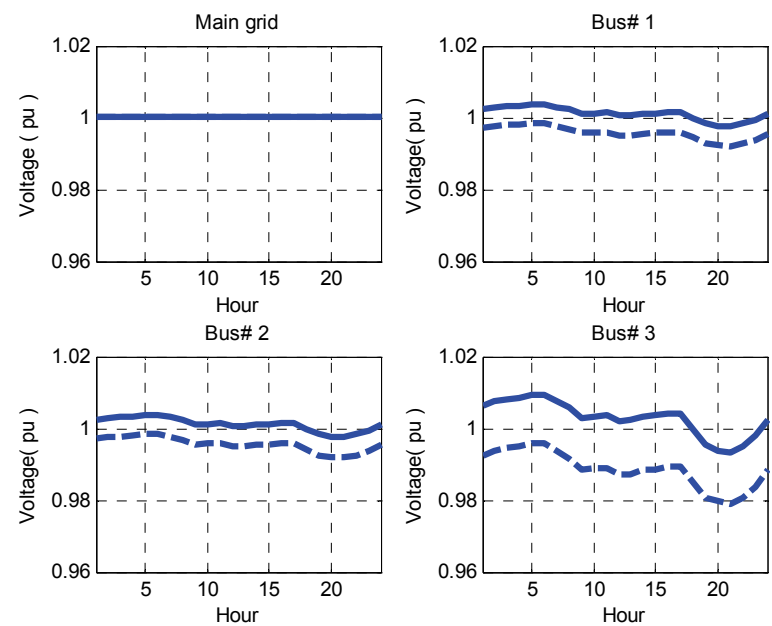

Figure 2. Voltage at buses 1, 2, 3 and main grid for single feeder network with and without using $\mu$ sources.
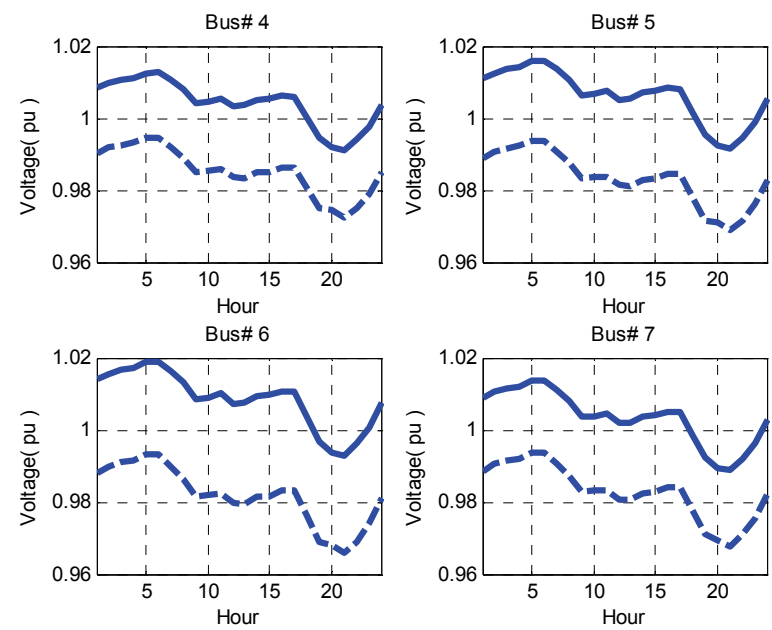

Figure 3. Voltage of buses 4, 5, 6 and 7 for single feeder network with and without using $\mu$ sources. 

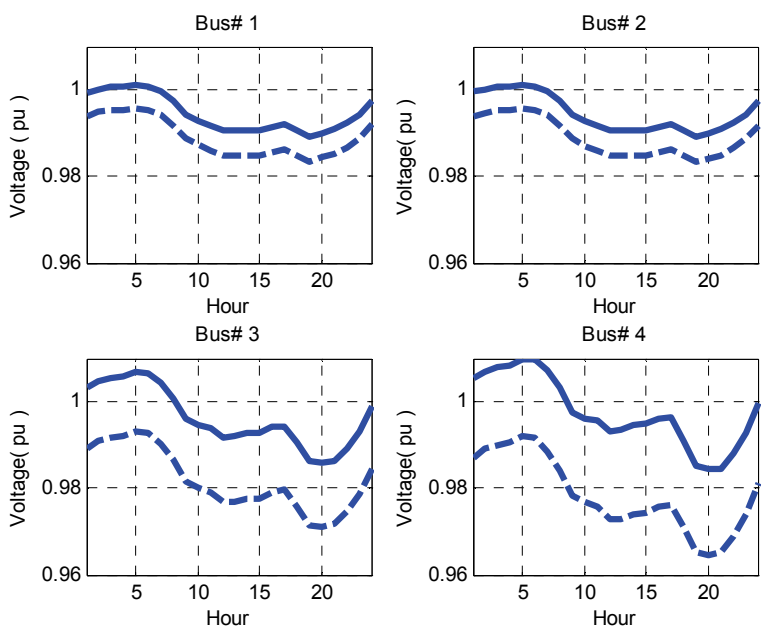

Figure 4. Voltage of buses 1, 2, 3 and 4 for three feeder network with and without using $\mu$ sources.
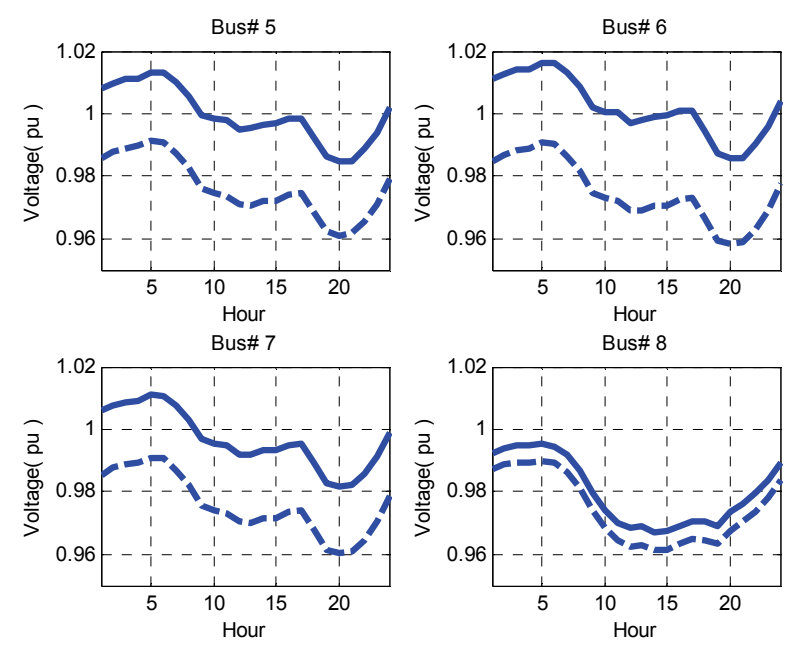

Figure 5. Voltage at buses 5, 6, 7 and 8 for three feeder network with and without using $\mu$ sources.
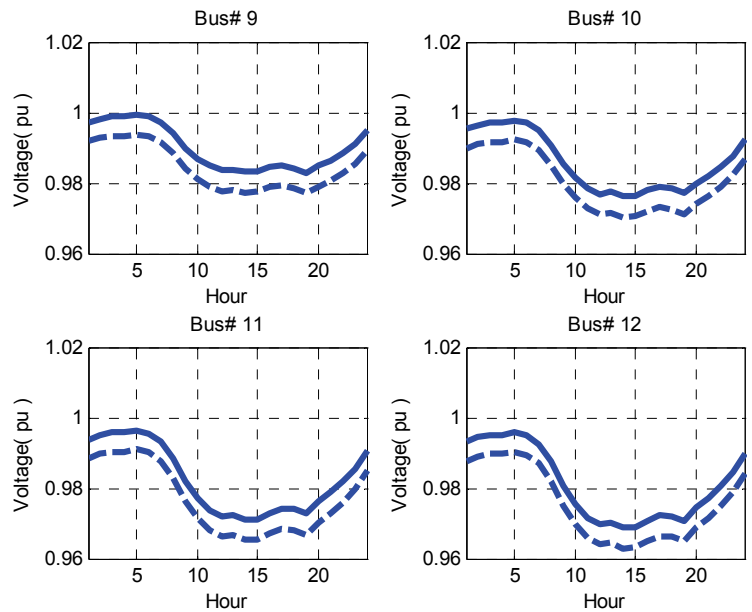

Figure 6. Voltage at buses 9, 10, 11 and 12 for three feeder network with and without using $\mu$ sources.
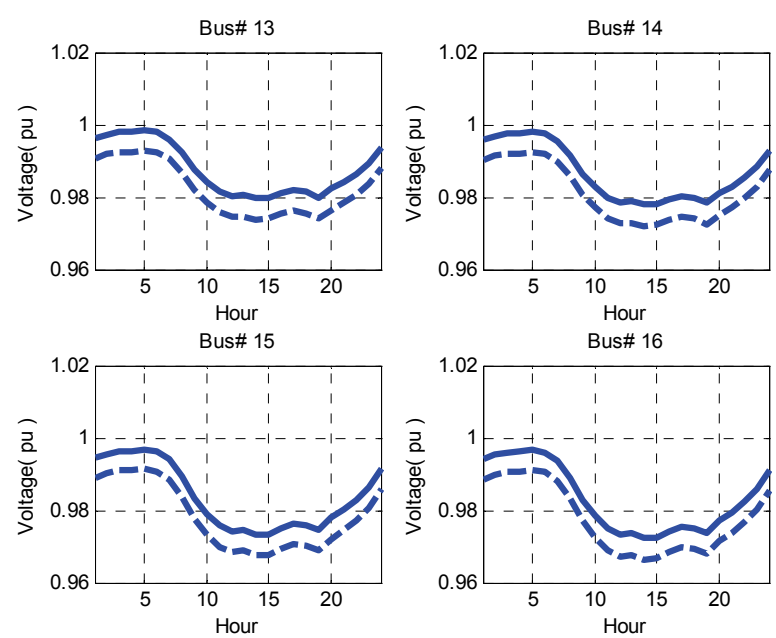

Figure 7. Voltage of buses 13, 14, 15 and 16 for three feeder network with and without using $\mu$ sources.

of power produced by the $\mu$ sources is less than the power demand by loads of the three feeder, also the $\mu$ sources are far from loads of industrial (bus 8) and commercial (buses 9-16) feeders.

- The largest drop of the voltage is about $4.5 \%$ without $\mu$ sources, because we assume that the voltage at the main grid (distribution network) equal to 1 p.u., if we assume that the voltage at the distribution network less than 1 p.u (due to voltage drop in the transmission network) as actually occur, the voltage drop without using $\mu$ sources will be more than $4 \%$ and may be reach to $8 \%$.

The total power losses for one feeder and three feeder networks at the same conditions mentioned before are evaluated and the results are shown in Figures 8 and 9.

From the above figures, the following points can be summarized:

- The total power losses with using $\mu$ sources is less than the losses when $\mu$ sources are not used, because using $\mu$ sources reduces the distance between the load and generation and also, reduce the current flowing from the main grid. In addition, in our analysis, we calculated the losses in the transformer which connect the main grid with the micro grid network. If we take the losses in the upper distribution and transmission networks, the amount of losses will exceed the calculated value.

- For single feeder network, at lightly load $\mu$ sources production will feeds the load and export the remaining power to the distribution grid which make the losses with using $\mu$ sources larger than losses without $\mu$ sources.

\section{Emission Reduction Evaluation with Using $\mu$ Sources}

In order to evaluate the potential of environmental benefits from the micro grids, data about the emissions from 


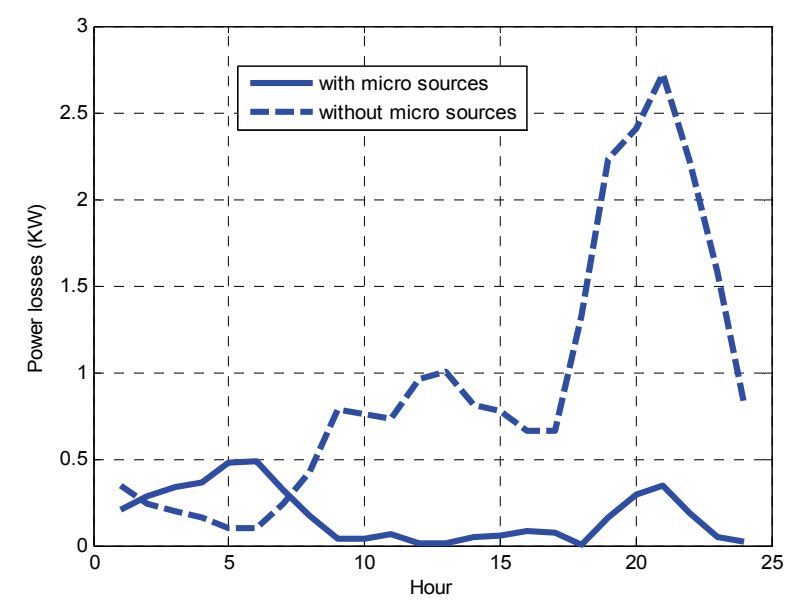

Figure 8. Total losses for single feeder network with and without $\mu$ sources.

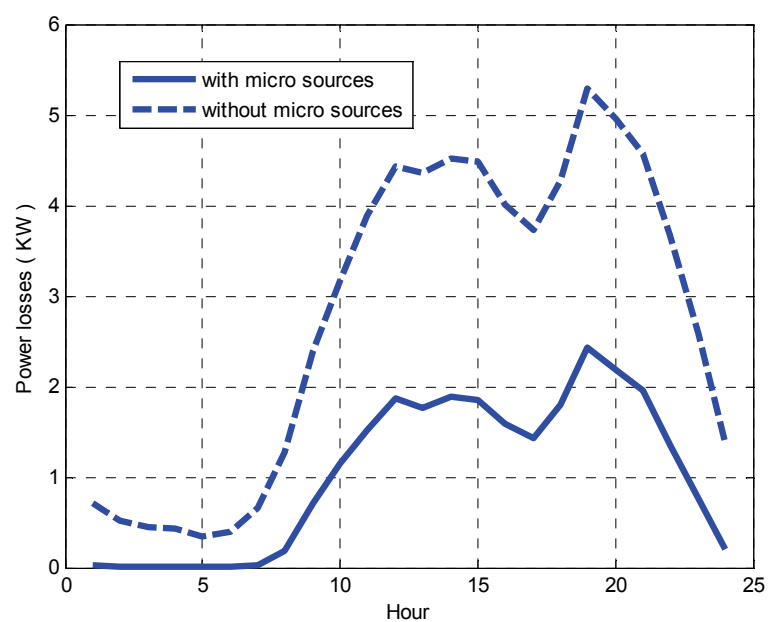

Figure 9. Total losses for three feeders network with and without $\mu$ sources.

the main grid and data about the emissions of the $\mu$ sources should be taken into account. The emissions for which calculations are made are: $\mathrm{CO}_{2}, \mathrm{SO}_{2}, \mathrm{NO}_{\mathrm{x}}$ and particulate matters.

\subsection{Emissions of the Main Grid}

The production of the $\mu$ sources displaces power from the main grid. Thus the emissions avoided are an average value of the main grid emissions multiplied by the production of the $\mu$ sources. In our study, typical values of emissions have been used as shown in Table 4 [7].

Table 4. Typical values of emissions from the main grid.

\begin{tabular}{cc}
\hline Pollutants & $\mathrm{gr} / \mathrm{KWh}$ \\
\hline $\mathrm{CO}_{2}$ & 889 \\
$\mathrm{SO}_{2}$ & 1.8 \\
$\mathrm{NO}_{\mathrm{x}}$ & 1.6 \\
Particulate Matters & 0.501 \\
\hline
\end{tabular}

\subsection{Impact of $\boldsymbol{\mu}$ Sources}

From the installed $\mu$ sources the ones that consume fuels have emissions which are significantly lower than the ones in the main grid. Where as the renewable such as wind and solar energies have zero emissions in their operation. It is assumed that the fuel burned by the Micro turbine and the fuel cells is natural gas. Table 5 gives the data used for our analysis [7].

\subsection{Results and Discussions}

Amounts of emissions with and without using $\mu$ sources for single feeder and three feeder networks are shown in Figures 10 and 11.

According to the results obtained in the previous figures the following point can be summarized:

- Using $\mu$ sources has large effect in reducing the amount of emissions on $\mathrm{CO}_{2}, \mathrm{SO}_{2}, \mathrm{NO}_{\mathrm{x}}$ and particulate matters, but the reduction in $\mathrm{SO}_{2}, \mathrm{NO}_{\mathrm{x}}$ and particulate matters is greater in percentage than $\mathrm{CO}_{2}$ reduction due to the fact that the fuel burning units use natural gas that has lower emission levels in particulate matters, $\mathrm{NO}_{\mathrm{x}}$ and $\mathrm{SO}_{2}$ compared to thermal stations that use Heavy Oil.

Table 5. Typical emission data for $\mu$ sources.

\begin{tabular}{ccccc}
\hline Unit name & $\begin{array}{c}\mathrm{CO}_{2} \text { coeff. } \\
(\mathrm{gr} / \mathrm{KWh})\end{array}$ & $\begin{array}{c}\mathrm{NO}_{\mathrm{X}} \text { coeff. } \\
(\mathrm{gr} / \mathrm{KWh})\end{array}$ & $\begin{array}{c}\mathrm{SO}_{2} \text { coeff. } \\
(\mathrm{gr} / \mathrm{KWh})\end{array}$ & $\begin{array}{c}\text { Parti. } \\
\text { Matters } \\
(\mathrm{gr} / \mathrm{KWh})\end{array}$ \\
\hline $\begin{array}{c}\text { Micro } \\
\text { Turbine }\end{array}$ & 724.6 & 0.2 & 0.004 & 0.041 \\
Fuel Cell & 489 & 0.01 & 0.003 & 0.001 \\
Wind1 & 0 & 0 & 0 & 0 \\
$\mathrm{PV}_{1}$ & 0 & 0 & 0 & 0 \\
$\mathrm{PV}_{2}$ & 0 & 0 & 0 & 0 \\
$\mathrm{PV}_{3}$ & 0 & 0 & 0 & 0 \\
$\mathrm{PV}_{4}$ & 0 & 0 & 0 & 0 \\
$\mathrm{PV}_{5}$ & 0 & 0 & 0 & 0 \\
\hline
\end{tabular}
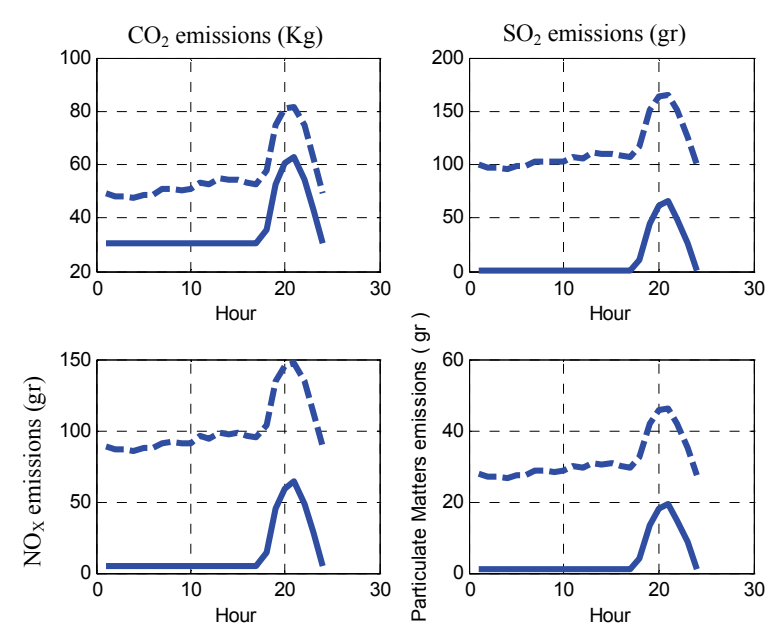

Figure 10. Amount of $\mathrm{CO}_{2}, \mathrm{SO}_{2}, \mathrm{NO}_{\mathrm{x}}$ and particulate matters emissions for one feeder network with and without $\mu$ sources. 

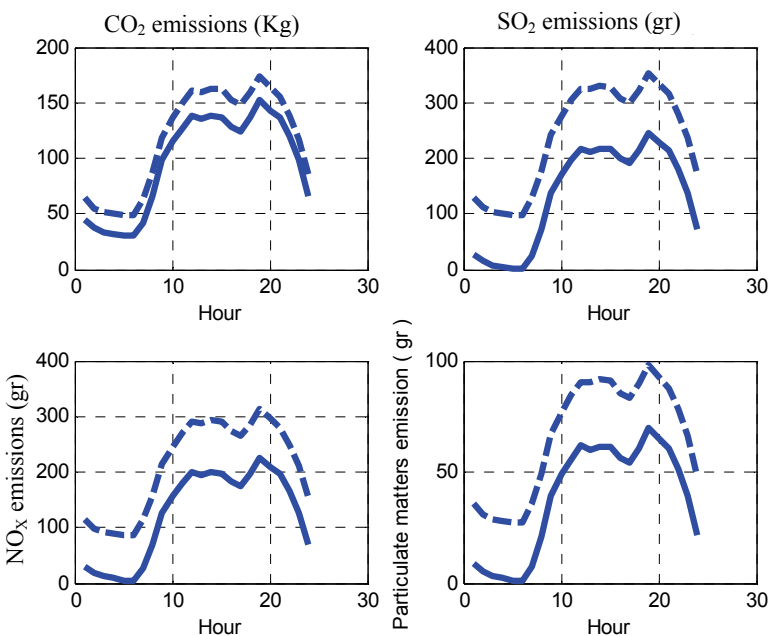

Figure 11. Amount of $\mathrm{CO}_{2}, \mathrm{SO}_{2}, \mathrm{NO}_{\mathrm{x}}$ and particulate matters emissions for three feeder network with and without $\mu$ sources.
- In our study, the amount of power produced by renewable energy is small ( $15 \%$ of the $\mu$ sources power), if the renewable sources increases, amount of emissions reduction will be more than the value shown in the previous figures.

\section{Conclusions}

Distributed generation (DG) operation can improve the voltage profile in the micro grid nodes especially at the feeder where $\mu$ sources are installed. Therefore the installation of DG sources seems to be a solution in improving the voltage profile within a micro grid during times of low voltages (peak loads). It is found that when the power produced by $\mu$ sources sufficient to loads, the voltage drop at all buses has a negligible values, also, using micro grid will decrease the amount of power losses because the power which produced by $\mu$ sources will consumed locally with the load near from the $\mu$

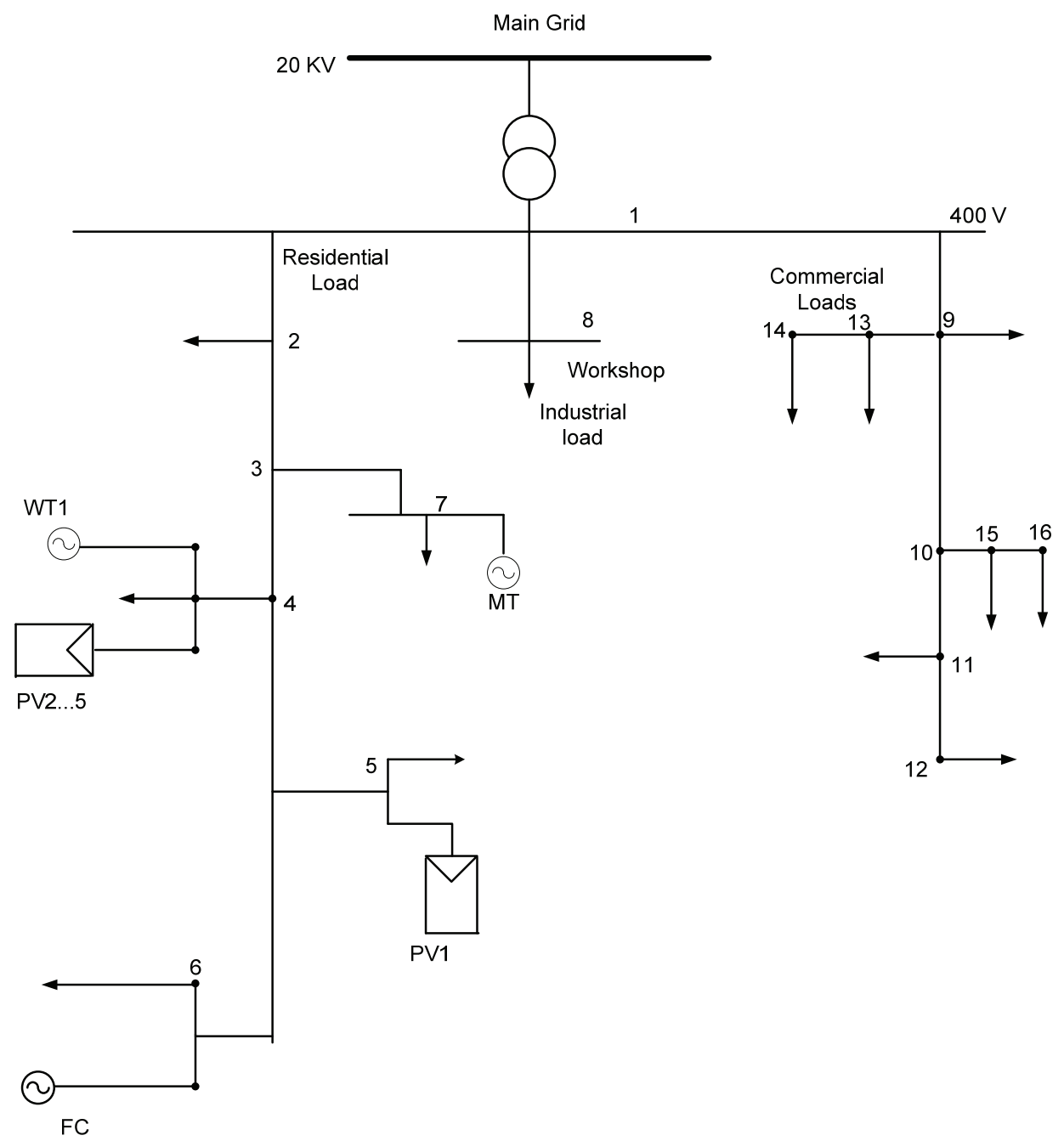

Figure 12. Single line diagram for three feeder network. 
sources which prevent current from flowing or circulating in the networks transmission lines. Results showed that using $\mu$ sources has more effects in reducing all types of emissions especially when the $\mu$ sources contains many renewable sources such as wind and solar energy sources. The authors next step research aims to study the effects of micro grid in the dynamic performance of the main grid and how to use the $\mu$ sources to solve some of power system dynamic problems such as voltage stability, power quality and power system reliability.

\section{REFERENCES}

[1] EU Project, "MICROGRIDS: Large Scale Integration of Micro-Generation to Low Voltage Grids (ENK5-CT-200200610)". http://microgrids.power.ece.ntua.gr/

[2] R. Lasseter, A. Akhil, C. Marnay, J. Stephens, J. Dagle, R. Guttromson, A. S. Meliopoulos, R. Yingerand and J. Eto, "White Paper on Intergration of Distributed Energy Resources - The CERTS MicroGrid Concept," LBNL.50829, U S Department of Energy, Office of Power Technologies,
Contract DE-AC03-76SF00098, 2002.

[3] European Research Project MicroGrids. http://microgrids. power.ece.ntua.gr/

[4] D. Pudjianto, E. Zafiropoulos and L. Daoutis, "DG4: Methodology for Quantifying Economic and Environmental Benefits of MicroGrids," Microgrids Project deliverable of task DG4, 2005.

[5] R. Billinton, M. Fotuhi-Firuzabad and L. bertling, "Bibliography on the Application of Probability Methods in Power System Reliability Evaluation 1996-1999," IEEE Power Engineering Review, Vol. 21, No. 8, 2001, p. 56.

[6] S. Papathanassiou, N. Hatziargyriou and K. Strunz, "A Benchmark Low Voltage Microgrid Network," Proceedings of the CIGRE Symposium: Power Systems with Dispersed Generation, Athens, 2005, pp. 1-8.

[7] A. Tsikalakis, I. Cobelo and J. Oyarzabal, "DC2: Evaluation of the MicroGrid Central Controller Strategies," Microgrids project deliverable of task DC2, 2004. http://microgrids.power.ece.ntua.gr

[8] H. Saadat, "Power System Analysis," McGraw-Hill Companies, New York, 1999. 